\title{
Caffeine Acetylator Phenotyping during Maturation in Infants
}

\author{
ANN PARIENTE-KHAYAT, GERARD PONS, ELISABETH REY, MARIE-ODILE RICHARD, \\ PHILIPPE D'ATHIS, CLAUDE MORAN, JEAN BADOUAL, AND GEORGES OLIVE
}

\author{
Département de Pharmacologie Périnatale et Pédiatrique [A.P.-K., G.P., E.R., M.-O.R., C.M., G.O] and Service \\ de Pédiatrie B [J.B.], Hôpital Saint-Vincent de Paul, 75674 Paris Cedex 14, France and \\ Informatique Médicale, Hôpital du Bocage, Dijon, France [P.D.]
}

\begin{abstract}
Caffeine acetylator phenotype was studied during maturation in 54 8- to 447-d-old children hospitalized for minor disease (group A) and in five 3- to 630-dold children with Pierre Robin syndrome (group B). In group $A$, the children received $2.5 \mathrm{mg} / \mathrm{kg}$ caffeine orally once between birth and 15 mo. Group B patients were chronically treated with caffeine $(2.3$ to $15.8 \mathrm{mg} / \mathrm{kg} / \mathrm{d})$ for prevention of apneas, and the acetylator phenotype was serially determined. Phenotyping was performed on a spot urine sample collected 2-6 h after drug administration. Caffeine metabolites [5-acetylamino-6-formylamino-3methyl uracil (AFMU), 1-methylxanthine, 1-methyluric acid, 1,7-methyluric acid, and 1,7-methylxanthine] were measured using HPLC. Acetylator phenotype was determined on the basis of AFMU/1-methylxanthine (ratio 1) and AFMU/AFMU + 1-methyluric acid + 1-methylxanthine $+1,7$-methylxanthine $+1,7$-methyluric acid (ratio 2) molar ratios. In group A, all children were slow acetylators before $83 \mathrm{~d}$ of age (ratio $1<0.4$; ratio $2<0.08$ ), whereas older children included slow and fast acetylators. The acetylation molar ratios differed significantly between age groups and increased with age. The cumulative percentage of fast acetylators increased with age but the plateau was not yet reached at $15 \mathrm{mo}$. In three children, the phenotyping was repeated after $15 \mathrm{mo}$ : the second determination was consistent with the first one. In group B, all children appeared as slow acetylators on the first phenotyping. Four of them appeared subsequently as fast acetylators; one remained a slow acetylator until 11 mo. These results suggest that maturation of caffeine acetylation occurs during at least the first $\mathbf{1 5}$ mo of life for fast acetylators but is not detectable in slow acetylators. Acetylator status cannot reliably be determined before at least $15 \mathrm{mo}$. (Pediatr Res 29: 492-495, 1991)
\end{abstract}

\section{Abbreviations}

AFMU, 5-acetylamino-6-formylamino-3-methyl uracil NAT, N-acetyltransferase

1U, 1-methyluric acid

1,7U, 1,7-methyluric acid

1X, 1-methylxanthine

$1,7 \mathrm{X}, 1,7$-methylxanthine

Acetylation is an important pathway in the biotransformation of drugs. At least 15 drugs are metabolized in man by the

Received June 29, 1990; accepted November 19, 1990.

Correspondence and reprint requests: G. Pons, M.D., Ph.D., Department de Pharmacologie Périnatale et Pédiatrique, Hôpital Saint Vincent de Paul, 74, Avenue Denfert Rochereau, 75674 Paris Cedex 14, France. polymorphic NAT system $(1,2)$. The clinical consequences of this polymorphism are extensive and include an increased susceptibility to adverse reactions, variations in therapeutic response, and occurrence of diseases $(1,3-10)$.

Caffeine is metabolized in man by the polymorphic NAT with formation of an N-acetylated metabolite: AFMU (11). In view of its widespread use and relative safety, caffeine has been shown to be a good in vivo probe of hepatic NAT activity. Measuring two molar ratios, AFMU/1X and AFMU/AFMU + $1 U+1 \mathrm{X}$ $+1,7 \mathrm{U}+1,7 \mathrm{X}$, on a spot urine sample after caffeine intake has been demonstrated to be a simple method to distinguish fast and slow acetylators of caffeine $(12,13)$. Previous studies in the neonate and infant suggested that acetylation was not mature in the neonate $(14,15)$ and that maturation occurred within the first 12 mo of life (15), precluding a reliable phenotyping for caffeine $\mathrm{N}$-acetylation before 1 y of age (15).

This study was undertaken to further describe the maturation of caffeine $\mathrm{N}$-acetylation and to determine at what age a reliable phenotyping can be obtained.

\section{MATERIALS AND METHODS}

Subjects. The acetylator phenotype was determined in a group of 54 children (group A) hospitalized in the Department of Pediatrics of Saint-Vincent de Paul Hospital for a minor disease (bronchiolitis: 26; fever: 7; diarrhea: 6; tonsillitis: 1; otitis: 4, Down syndrome: 2 ; and other pathology: 8 ) and in a group of five children with Pierre Robin syndrome (group B). Group A was composed of 31 boys and 23 girls (42 Caucasians, six blacks, and six North Africans), 8 to $447 \mathrm{~d}$ old. Group B was composed of two boys and three girls (four Caucasians and one North African) treated with caffeine for prevention of apneas; they were serially studied between 3 and $630 \mathrm{~d}$ of age. We tested the reliability of our assay method in 30 healthy unrelated Caucasians, 15 men and 15 women aged between 20 and $56 \mathrm{y}$.

Protocol. In group A, the acetylator phenotype was studied once between birth and 15 mo of age, when the acute illness was over, just before discharge. Three of the children were restudied between 15 and 18 mo of age in the outpatient clinic to ascertain the final acetylator phenotype, assuming maturation at that age was completed (15). Children in group A were given a single 2.5$\mathrm{mg} / \mathrm{kg}$ oral dose of an aqueous solution of caffeine citrate early in the morning, $30 \mathrm{~min}$ before bottle feeding or breakfast. Children in group B, treated with caffeine, were studied at steady state. They received their usual caffeine citrate oral dose in the morning $30 \mathrm{~min}$ before bottle feeding. Caffeine dose had been adjusted by plasma concentration determination and varied from 2.3 to $15.8 \mathrm{mg} / \mathrm{kg} / \mathrm{d}$. Vitamins, fluorine, and antibiotics excep 1 erythromycin were allowed during the test, but antituberculou: drugs were not. None of the children had any history of hepatic disease and none was receiving any drug known to affect meth. 
ylxanthine metabolism. Informed consent was obtained from the parents. The adult subjects received a single $3-\mathrm{mg} / \mathrm{kg}$ caffeine oral dose.

Urine collection. A spot urine sample was collected between 2 and $6 \mathrm{~h}$ after caffeine dosing and placed at $4^{\circ} \mathrm{C}$. Urinary $\mathrm{pH}$ was measured and the sample was quickly frozen to $-20^{\circ} \mathrm{C}(11)$.

Analytical procedures. The analytical methods were those described by Grant et al. (2) with a few modifications. For AFMU, the chromatographic conditions were as follows: the column was an Ultrasphere Octa Decyl Silane $5-\mu \mathrm{m}$ particle size, $25 \mathrm{~cm} \times 2$ mm (Beckman, San Ramon, CA); the eluant was a mixture of $88 \% 0.1 \mathrm{M}$ monobasic ammonium phosphate and $12 \%$ methanol; and the flow rate was $0.3 \mathrm{~mL} / \mathrm{min}$. A $1-\mathrm{g} / \mathrm{L}$ acetaminophen solution was used as internal standard. For $1 \mathrm{U}, 1 \mathrm{X}, 1,7 \mathrm{U}$, and $1,7 \mathrm{X}$, a $50 \mathrm{mg} / \mathrm{L}$ diphylline solution in a $0.002 \mathrm{M}$ aqueous solution of sodium hydroxide was used as internal standard (16). For $1 \mathrm{U}$ and $1 \mathrm{X}$, the eluant was a mixture of $95 \% 0.1 \mathrm{M}$ monobasic ammonium phosphate and $5 \%$ methanol at a flow rate of $0.2 \mathrm{~mL} / \mathrm{min}$. For $1,7 \mathrm{U}$ and $1,7 \mathrm{X}$, the eluant was a mixture of $85 \% 0.1 \mathrm{M}$ monobasic ammonium phosphate and $15 \%$ methanol. For each metabolite, the standard curve was linear between 0 and $20 \mathrm{mg} / \mathrm{L}$. The coefficients of variation calculated in 10 samples of a $10-\mathrm{mg} / \mathrm{L}$ solution were $2.3,6,3.6,5.9$, and $5.3 \%$ for AFMU, 1U, IX, 1,7U, and 1,7X, respectively. The coefficients of extraction were 100 (chloroform), 34, 76, 80, 83, and $66 \%$ (chloroform, isopropanol: 50/50) for AFMU, 1U, 1X, 1,7U, $1,7 \mathrm{X}$, and acetaminophen, respectively.

Source of metabolites and reagents. Acetaminophen, $1 \mathrm{U}, 1,7 \mathrm{U}$, and 1,7X were obtained from Sigma Chemical Co., (St. Louis, MO) and IX from Fluka (Buchs, Switzerland). AFMU was synthetized by Dr. Fourrey from CNRS Laboratory (Orsay, France). Diphylline was from Serlabo (Paris, France). Chloroform Lichrosolv and ammonium sulfate (in crystal form) were from Merck (Nogent, France). Isopropanol, acetic acid, methanol, and monobasic ammonium phosphate were from Prolabo (Paris, France).

Calculations. The acetylator phenotype was calculated using the AFMU/1X (ratio 1) and AFMU/AFMU + 1U + 1X + 1,7U $+1,7 \mathrm{X}$ (ratio 2) molar ratios. The values of these molar ratios enabled the subjects to be classified as slow acetylators (ratio 1 $<0.4$, or ratio $2<0.08$ ) and fast acetylators (ratio $1>=0.4$, or ratio $2>=0.08$ ) according to the antimodes of the distribution of the ratios previously described in the literature $(2,12)$.

Statistical analysis. Statistical analysis was performed with our own software, Triomphe. Mean acetylator molar ratios were calculated in different age groups. The proportion of fast acetylators was compared in each group using a $\chi^{2}$ test. The cumulative proportion of fast acetylators was calculated as a function of age. In each child of group B, we tested against 0 the linear correlation coefficient between each acetylation ratio and the caffeine dose. Results are expressed as mean $\pm \mathrm{SD}$.

\section{RESULTS}

Initial phenotyping in group A. Ratio 1 was calculated in 52 out of 54 children. In the two remaining children, the amount of urine collected was too small to determine $1 \mathrm{X}$ concentration. Ratio 2 was calculated in only 40 out of 54 children. In the 14 remaining children, the amount of urine collected was too small to determine the concentration of all metabolites.

All children studied before the age of $83 \mathrm{~d}$ appeared as slow acetylators with both ratios. The acetylation ratio increased with age during the first year of life (Fig. 1). The 54 children of group A were separated into five classes of roughly equal numbers: 8$55,56-121,122-224,225-242$, and $243-447 \mathrm{~d}$ of age. A significant difference was found for the proportion of fast acetylators, calculated with ratio 1 , between age groups by a $\chi^{2}$ test $(p<$ 0.05 ) (Table 1). The difference did not reach statistical significance with ratio 2 . The cumulative frequency of fast acetylators is shown in Figure 2.
Second phenotyping in group A. A second phenotyping was possible in three children. Two children identified as slow acetylators on the initial phenotyping at $11 \mathrm{mo}$ (ratio $1=0.077$, ratio 2 not determined) and 13 mo of age (ratio $1=0.05$, ratio $2=0.017$ ), respectively, were still slow acetylators at 21 (ratio 1 $=0.24$, ratio $2=0.03$ ) and $23 \mathrm{mo}$ (ratio $1=0.12$, ratio $2=$ $0.04)$, respectively. The third child classified as a fast acetylator on the initial phenotyping at $8 \mathrm{mo}$ (ratio $1=1.6$; ratio $2=0.2$ ) remained a fast acetylator at $20 \mathrm{mo}$ (ratio $1=6.9$; ratio $2=$ 0.09 ).

Sequential phenotyping in group $B$. The acetylator phenotype was determined in five children, $5,6,10,8$, and 6 times between 4 and $21 \mathrm{mo}, 2 \mathrm{mo}$ and $1 \mathrm{y}, 27 \mathrm{~d}$ and $11 \mathrm{mo}, 3 \mathrm{~d}$ and $7 \mathrm{mo}$, and $31 \mathrm{~d}$ and $4 \mathrm{mo}$ of age, respectively (Fig. 3). The five children tested appeared as slow acetylators on the initial phenotyping performed between $3 \mathrm{~d}$ and 5 mo of age. One child remained a slow acetylator during the nine subsequent phenotypings performed between $27 \mathrm{~d}$ and $11 \mathrm{mo}$ of age. The four others appeared subsequently as fast acetylators. However, in these children the values of the two acetylation molar ratios varied substantially. To explain these variations, we sought in each child an influence of the caffeine dose on the acetylation ratios. In all children but one, the correlation was not significant. In child 4 , a significant correlation was evidenced between ratio 2 and caffeine dose ( $r=$ $0.91, p<0.01$ ) but not between ratio 1 and caffeine dose.

Phenotyping in adults. We found $50 \%$ to be slow acetylators (ratio $1=0.19 \pm 0.069$, ratio $2=0.0527 \pm 0.052$ ) and $50 \%$ to be fast acetylators (ratio $1=1.24 \pm 0.337$, ratio $2=0.196 \pm$ $0.08)$.

\section{DISCUSSION}

The two molar ratios, ratios 1 and 2, were used as a probe of NAT activity (13). This is an indirect means to determine the acetylation phenotype. For ethical reasons, it is not possible to measure NAT activity in liver biopsy in children. Recently, Grant et al. (17) showed a strong correlation $(r=0.98)$ between the in vivo urinary AFMU/1X ratio after caffeine administration in 14 subjects and NAT activity measured in vitro in liver wedge biopsies of the same subjects.

The method used offers a number of practical advantages. It requires the oral intake of a low dose of a very popular, ubiquitous, and safe drug. Caffeine is already used in children for therapeutic purposes. Moreover, this method does not require any plasma sampling, only a urine spot sample. This method has, however, been recently criticized, especially because of the physicochemical properties of AFMU and IX. AFMU has been shown to be an unstable compound in vitro at ambient temperature at a pH above $3.5(13,18)$. $1 \mathrm{X}$ is poorly soluble in water and may concentrate in urine and precipitate at low temperatures (18). Tang et al. (19) demonstrated that urine centrifugation could decrease $1 \mathrm{X}$ concentration by more than $50 \%$ in the supernatant. To prevent these phenomena in our study, urine samples were placed at $4^{\circ} \mathrm{C}$ immediately after collection and frozen quickly to $-20^{\circ} \mathrm{C}$. Urine samples were not centrifuged, to avoid precipitation of $1 \mathrm{X}$, but were homogenized before analysis. The results obtained in adult subjects in testing the reliability of our assay method are consistent with those reported in the literature on a Caucasian population $(20,21)$. Molar ratio 2 was calculated to confirm the results obtained with ratio 1 . Results obtained with both ratios were consistent in all subjects but one, a child with Pierre Robin syndrome, who appeared at 2 mo of age as a "borderline" fast acetylator $(0.41)$ with ratio 1 and as a slow acetylator $(0.037)$ with ratio 2 .

The increase in acetylator ratios and in the proportion of fast acetylators during the first year of life suggests a postnatal maturation of caffeine $\mathrm{N}$-acetylation. The study of the cumulative percentage of fast acetylators as a function of age suggests that the plateau is not yet reached at $15 \mathrm{mo}$ of age and that the maturation of caffeine $\mathrm{N}$-acetylation is not completed at that 

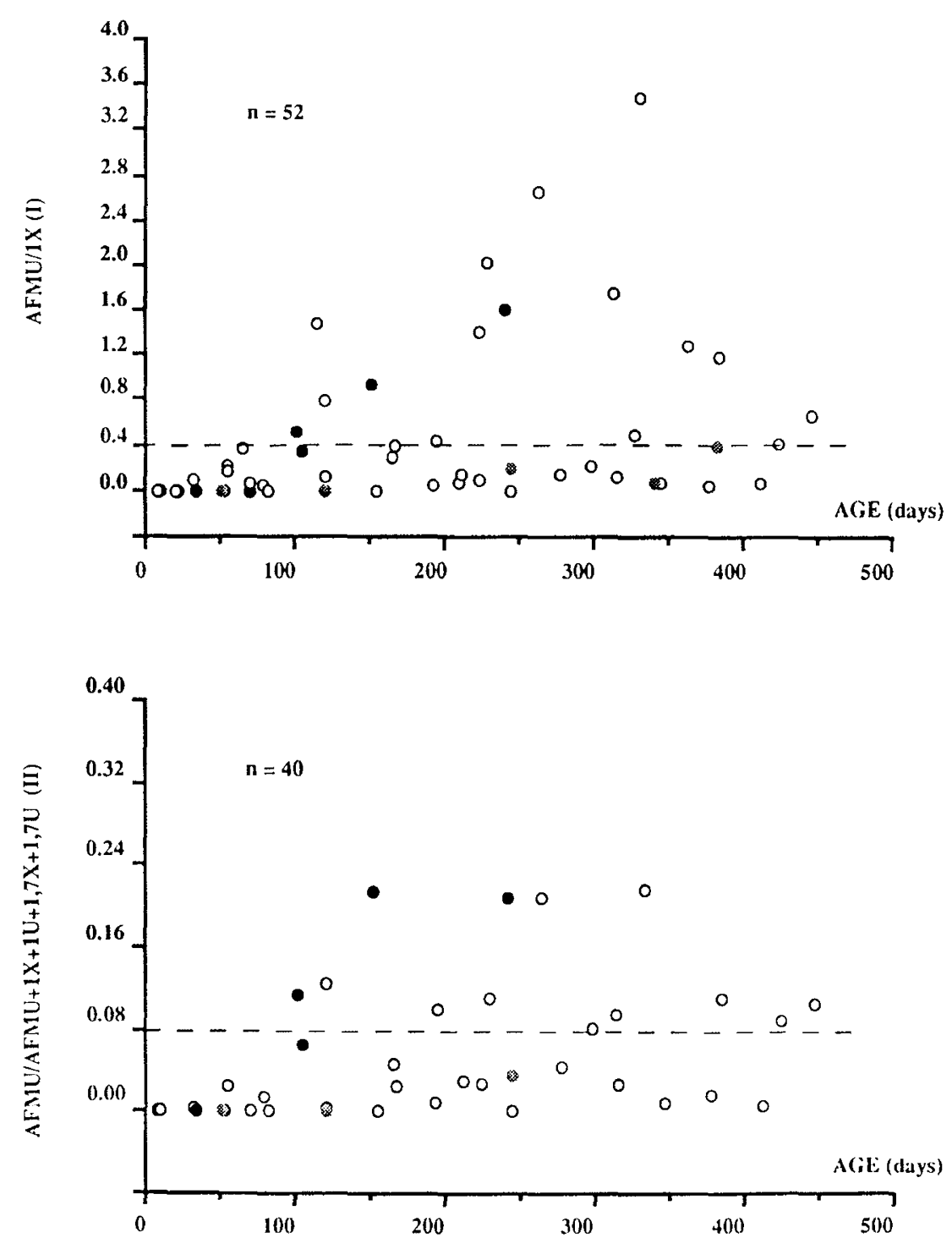

Fig. 1. AFMU/1X (ratio 1) and AFMU/AFMU + 1X + 1U + 1,7X + 1,7U (ratio 2) caffeine acetylation molar ratios as a function of age, determined only once, after a single $2.5 \mathrm{-mg} / \mathrm{kg}$ caffeine oral dose, in 52 (top) and 40 (bottom) children of different ages between birth and $15 \mathrm{mo}$, hospitalized for a mild pathology (group A). (The antimode of the distribution for ratios 1 and 2 is represented by a dotted line.) Ratio 1 was calculated in only 52 [caucasian: $41(0)$; North African: $5(\odot)$; black: $6(\bullet)$ ] and ratio 2 in only 40 (caucasian: 32 ; North African: 3 ; black: 5 ) out of 54 children because the amount of urine collected was too small in some of them to determine the concentration of all metabolites.

Table 1. Caffeine acetylation molar ratios and percentage of fast acetylators, in five age groups, in children

\begin{tabular}{|c|c|c|c|c|c|c|}
\hline & \multicolumn{5}{|c|}{ Age groups (d) } & \multirow[b]{2}{*}{$\chi^{2}(4 d f)$} \\
\hline & $0-55$ & $56-121$ & $122-224$ & $225-342$ & $343-447$ & \\
\hline AFMU/1X molar ratio (mean $\pm \mathrm{SD}$ ) & $0.032 \pm 0.071$ & $0.32 \pm 0.43$ & $0.38 \pm 0.45$ & $1.06 \pm 1.19$ & $0.51 \pm 0.48$ & \\
\hline Fast acetylators $(\%)$ & 0 & 25 & 30 & 50 & 62.5 & $p<0.05$ \\
\hline $\begin{array}{l}\mathrm{AFMU} /(\mathrm{AFMU}+1 \mathrm{U}+1 \mathrm{X}+1.7 \mathrm{U}+1.7 \mathrm{X}) \\
\text { molar ratio }(\text { mean } \pm \mathrm{SD})\end{array}$ & $0.00074 \pm 0.0015$ & $0.038 \pm 0.05$ & $0.057 \pm 0.07$ & $0.1 \pm 0.08$ & $0.057 \pm 0.05$ & \\
\hline Fast acetylators $(\%)$ & 0 & 22 & 25 & 60 & 50 & NS \\
\hline
\end{tabular}

age. Our results are different from those published by Meisel et al. (22), who suggested a rapid maturation of $\mathrm{N}$-acetylation during intrauterine life. They found that about $50 \%$ of the enzyme activity in adult fast acetylators were already observed in human fetal livers between the 9th and the 12th wk of gestation. These authors used procainamide as a substrate to measure the NAT activity. This apparent discrepancy with our results suggests that procainamide may be acetylated by a different NAT isoenzyme. Our results are consistent with those published by Szorady et al. (14), who found 83 out of 100 healthy Hungarian neonates to be slow acetylators using sulphadimidine as a probe.
The results obtained in five children with Pierre Robin syndrome sequentially phenotyped are consistent with those obtained in the other group of patients. The acetylation phenotyping was, however, performed under different conditions: the children were treated for a long period of time with caffeine, and the caffeine dose varied from 2.3 to $15.8 \mathrm{mg} / \mathrm{kg} / \mathrm{d}$. The absence of correlation between the acetylation molar ratio 1 and caffeine dose in most cases suggests no influence of the caffeine dose on the ratio value that could explain the variations of the acetylator ratio observed in the fast acetylators. These results are consistent with those published by Kalow et al. (23), who found no corre- 


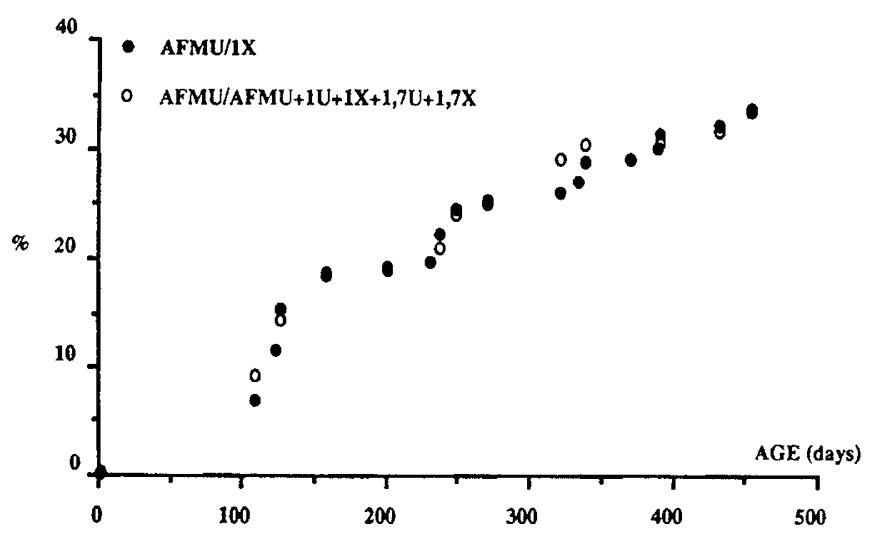

Fig. 2. Cumulative percentage of fast acetylators as a function of age in children in group A.
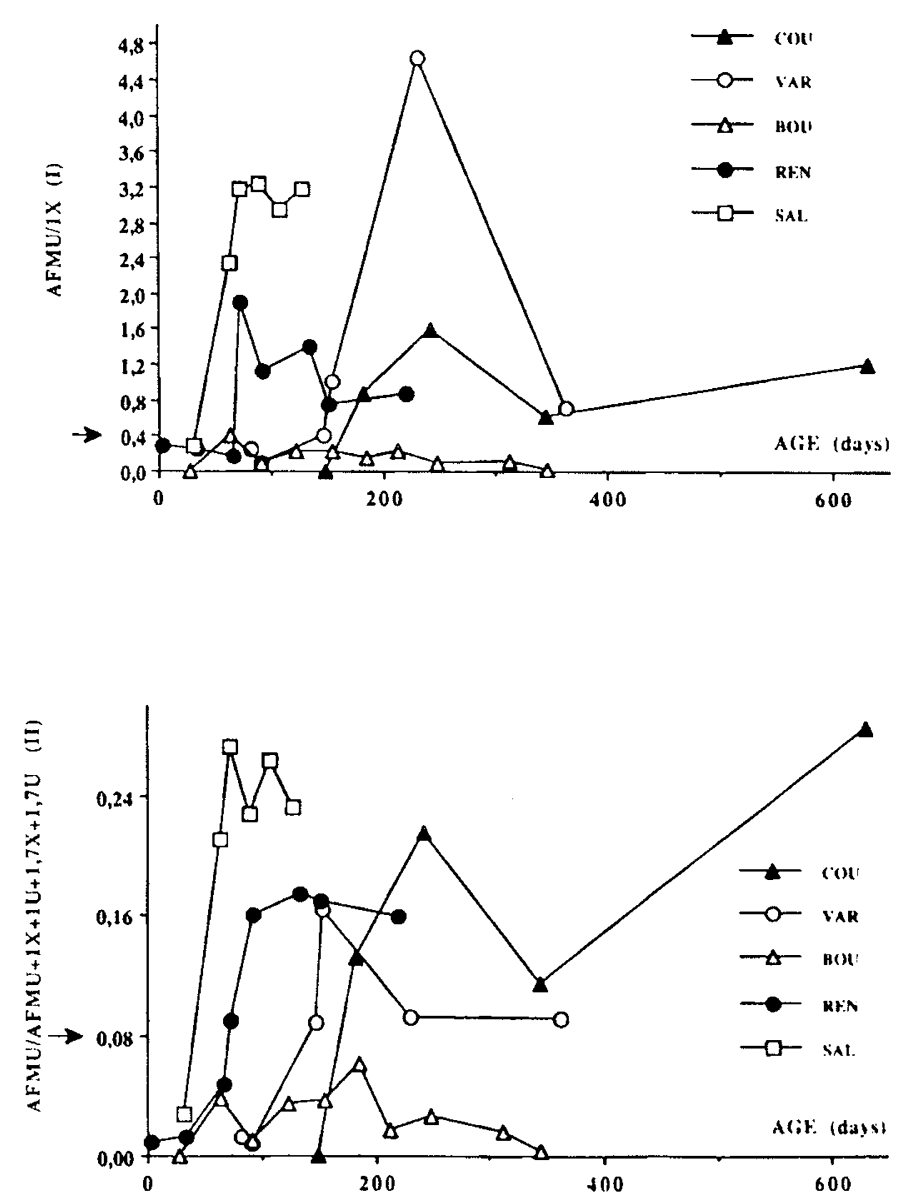

Fig. 3. AFMU/1X (ratio 1) and AFMU/AFMU + $1 \mathrm{X}+1 \mathrm{U}+1,7 \mathrm{X}$ $+1,7 \mathrm{U}$ (ratio 2) caffeine acetylation molar ratios as a function of age, serially determined in five children with Pierre Robin syndrome treated with caffeine for prevention of apneas (group B). The cut-off level for slow and fast acetylation is indicated with a horizontal arrow on the $y$ axis. lation between the ratios of metabolites and usual coffee consumption (0-9 cups per d), although in most cases our patients received caffeine doses much higher than those used by Kalow et al.

Our results confirm those observed by Pons et al. (15) in a previous preliminary study on the maturation of the caffeine $\mathrm{N}$ acetylation. They suggest that acetylator status cannot reliably be determined before at least 15 mo of age.

\section{REFERENCES}

1. Lunde PKM, Frislid K, Hansteen V 1977 Disease and acetylation polymorphism. Clin Pharmacokinet 2:182-197

2. Grant DM, Tang BK, Kalow W 1983 Polymorphic N-acetylation of a caffeine metabolite. Clin Pharmacol Ther 33:355-359

3. Cartwright RA, Glashan RW, Rogers HJ, Ahmad RA, Barham-Hall D, Higgins E, Kahn MA 1982 Role of N-acetyltransferase phenotypes in bladder carcinogenesis: a pharmacogenetic epidemiological approach to bladder cancer. Lancet 2:842-845

4. Drayer DE, Reidenberg MM 1977 Clinical consequences of polymorphic acetylation of basic drugs. Clin Pharmacol Ther 22:251-258

5. Clark DWJ 1985 Genetically determined variability in acetylation and oxidation. Therapeutic implications. Drugs 29:342-375

6. Wolf H, Lower GM, Bryan GT 1980 Role of N-acetyltransferase phenotype in human susceptibility to bladder carcinogenic arylamines. Scand J Urol Nephrol 14:161-165

7. Du Souich P, Lambert C 1981 What is the clinical meaning of the acetylator phenotype? Trends Pharmacol Sci: 189-191

8. Reidenberg MM, Levy M, Drayer DE, Zylber-Katz E, Robbins WC 1980 Acetylator phenotype in idiopathic systemic lupus erythematosus. Arthritis Rheum 23:569-573

9. Shenfield GM, McCann VJ, Tjokresetio R 1982 Acetylator status and diabetic neuropathy. Diabetologia 22:441-444

10. Stryjek-Kaminska D, Malczewski B, Kopec A, Rowinska-Marcinska K 1988 Acetylator phenotypes in diabetes mellitus. Acta Diabetol Lat 25:41-48

11. Tang BK, Grant DM, Kalow W 1983 Isolation and identification of 5acetylamino-6-formylamino-3-methyluracil as a major metabolite of caffeine in man. Drug Metab Dispos 11:218-220

12. Grant DM, Tang BK, Kalow W 1983 Variability in caffeine metabolism. Clin Pharmacol Ther 33.591-602

13. Grant DM, Tang BK, Kalow W 1984 A simple test for acetylator phenotype using caffeine. Br J Clin Pharmacol 17:459-464

14. Szorady I, Santa A, Veress I 1987 Drug acetylator phenotypes in newborn infants. Biol Res Pregnancy 8:23-25

15. Pons G, Rey E, Carrier O, Richard MO, Moran C, Badoual J, Olive G 1989 Maturation of AFMU excretion in infants. Fundam Clin Pharmacol 3:589595

16. Naline E, Flouvat B, Advenier C, Pays M 1987 Determination of theophylline and its metabolites in plasma and urine by reversed-phase liquid chromatography using an amine modifier. $J$ Chromatogr 419:177-189

17. Grant DM, Eichelbaum M, Meyer UA 1989 Genetic polymorphism of Nacetyltransferase: enzyme activity and content in liver biopsies correlate with acetylator phenotype determined with caffeine. Eur J Clin Pharmacol 36(suppl):A199(abstr)

18. Lorenzo B, Reidenberg MM 1989 Potential artifacts in the use of caffeine to determine acetylation phenotype. $\mathrm{Br} \mathrm{J}$ Clin Pharmacol 28:207-208

19. Tang BK, Zubovits T, Kalow W 1986 Determination of acetylated caffeine metabolites by high performance exclusion chromatography. J Chromatogr 375:170-173

20. Kalow W 1982 Ethnic differences in drug metabolism. Clin Pharmacokinet 7:373-400

21. Weber WW, Hein DW $1985 \mathrm{~N}$-acetylation pharmacogenetics. Pharmacol Rev 37:25-79

22. Meisel M, Schneider T, Siegmund W, Nikschick S, Klebingat KJ, Scherber A 1986 Development of human polymorphic N-acetyltransferase. Biol Res Pregnancy 7:74-76

23. Kalow W 1985 Variability of caffeine metabolism in humans. Arzneimittelforschung 35:319-324 